\title{
In vivo imaging of molecular targets and their function in endocrinology
}

\author{
Joanna E Burdette \\ Department of Medicinal Chemistry and Pharmacognosy, College of Pharmacy, University of Illinois at Chicago, 833 South Wood Street, Chicago, Illinois 60612, USA \\ (Correspondence should be addressed to J E Burdette; Email: joannab @ uic.edu)
}

\begin{abstract}
Imaging is one of the fastest growing fields of study. New technologies and multimodal approaches are increasing the application of imaging to determine molecular targets and functional processes in vivo. The identification of a specific target, transporter, or biological process using imaging has introduced major breakthroughs to the field of endocrinology primarily utilizing computed tomography, magnetic resonance imaging, ultrasonography, positron emission tomography, single-photon emission computed tomography, and optical imaging. This review provides a general background to the specific developments in imaging that pertains to in vivo function and target identification in endocrine-based diseases.
\end{abstract}

Journal of Molecular Endocrinology (2008) 40, 253-261

\section{Introduction}

The field of in vivo imaging offers the opportunity to define the morphological size and location of organs and diseased tissue in three dimensions. Accumulating studies indicate that the field of imaging can work toward providing patient-specific information, for example, in cancer the tumor localization, staging, and treatment follow-up response. The ability to detect abnormal masses of cells in the body allows the diagnosis of benign and malignant tumors as well as other changes in endocrinology. Advances in the imaging field provide the chance to couple these morphological datasets with functional biological pathways in an attempt to better understand the properties of specific organs in normal and diseased tissue.

Functional imaging is necessary because macroscopic alterations in tissues from disease are often the end result of changes that occurred in a molecular and signaling profile prior to the increase in growth. Locating and determining the size of an abnormal growth in one tissue might only reflect benign disease and not the need for medical intervention. In addition, knowing the size and location of a particular abnormal tissue would provide little or no information regarding the proper treatment strategy. Therefore, developing in vivo imaging modalities that depict changes in target expression and function are necessary for the field of endocrinology.

Journal of Molecular Endocrinology (2008) 40, 253-261

0952-5041/08/040-253 $\quad$ C) 2008 Society for Endocrinology Printed in Great Britain

\section{Imaging modalities}

Imaging technologies that report on the regulation of specific pathways involve positron emission tomography (PET), single-photon emission tomography (SPECT), magnetic resonance imaging (MRI), and optical imaging using fluorescence and bioluminescence. PET and SPECT utilize radiolabeled molecules to image the distribution of tracers within the body and report on the expression level of a target or the activity of cells. The advantage of PET and SPECT is the high-sensitivity level for detecting subtle biological changes using limited quantities of the imaging agent. SPECT gathers imaging information based on the amount of gamma-emitting radionucleotides that emit a single photon, but it is generally not as sensitive and less quantifiable than PET. PET detects biochemical processes in cells by measuring the positrons emitted by the probe as it decays and collides with electrons in vivo (Doubrovin et al. 2004, Herschman 2004). The PET emissions are two photons released $180^{\circ}$ from one another and detected in an array, which measure the volume and concentration of the probe (Blasberg 2002). MRI generally requires the use of contrast agents that increase the signal intensity of tissues containing the agent as compared with surrounding tissues (Allen \& Meade 2004). Most contrast agents use gadolinium (III) because of its high magnetic moment and the abundance of unpaired electrons. The ability of gadolinium to increase signal intensity relies on the interaction between unpaired 
electrons and water protons resulting in an increase in $\mathrm{T} 1$ and a longer signal. In general, gadolinium (III) is stably chelated due to toxicity of free gadolinium in the body. Superparamagnetic species are utilized in MRI as T2 agents. The large magnetic field of a superparamagnetic species decreases the signal intensity in tissues resulting in a contrast enhancement (Allen \& Meade 2003, Allen et al. 2004). Optical imaging often takes advantage of light transmission through a biological tissue. However, as many samples are hidden from light sources due to the interior location of the body, only small animals that are relatively transparent can be readily imaged. The targeted imaging approaches highlighted in this review are summarized in Fig. 1. Some of the advantages and disadvantages are also summarized in Table 1.

\section{Glucose metabolism}

Integral to the field of endocrinology is the process of glucose metabolism. The most commonly used PETagent for functional imaging clinically is fluorine-18-labeled deoxyglucose $\left({ }^{18} \mathrm{FDG}\right.$ or FDG). FDG is a glucose analog that is transported via glucose transporters (GLUTs) such as GLUT-1 and GLUT-3 (facilitated glucose transporter member 1) and type II hexokinase (Tohma et al. 2005, Zhao et al. 2005). Its metabolite, 2-fluorodeoxyglucose-6phosphate, is effectively trapped intracellularly and cannot undergo further metabolism. The rapid metabolism and uptake of glucose by cancer cells makes accumulation of the PET agent an excellent marker for malignant disease, dependent on the genetic expression of the various GLUTs (Mankoff $e t$ al. 2007). The efficiency of the tumor to accumulate FDG provides prognostic value for how well the patient will respond to chemotherapy, as the high metabolically activated state correlates with tumor cell division, the biological target of many chemotherapeutic drugs (Eriksson et al. 2005). Despite its widespread use and strengths, FDG-PET does not provide useful information for tumors that are relatively slow growing (Lewington \& Clarke 2001). Also, the spatial resolution of PET imaging makes the detection of small tumors difficult, especially if they are located near the

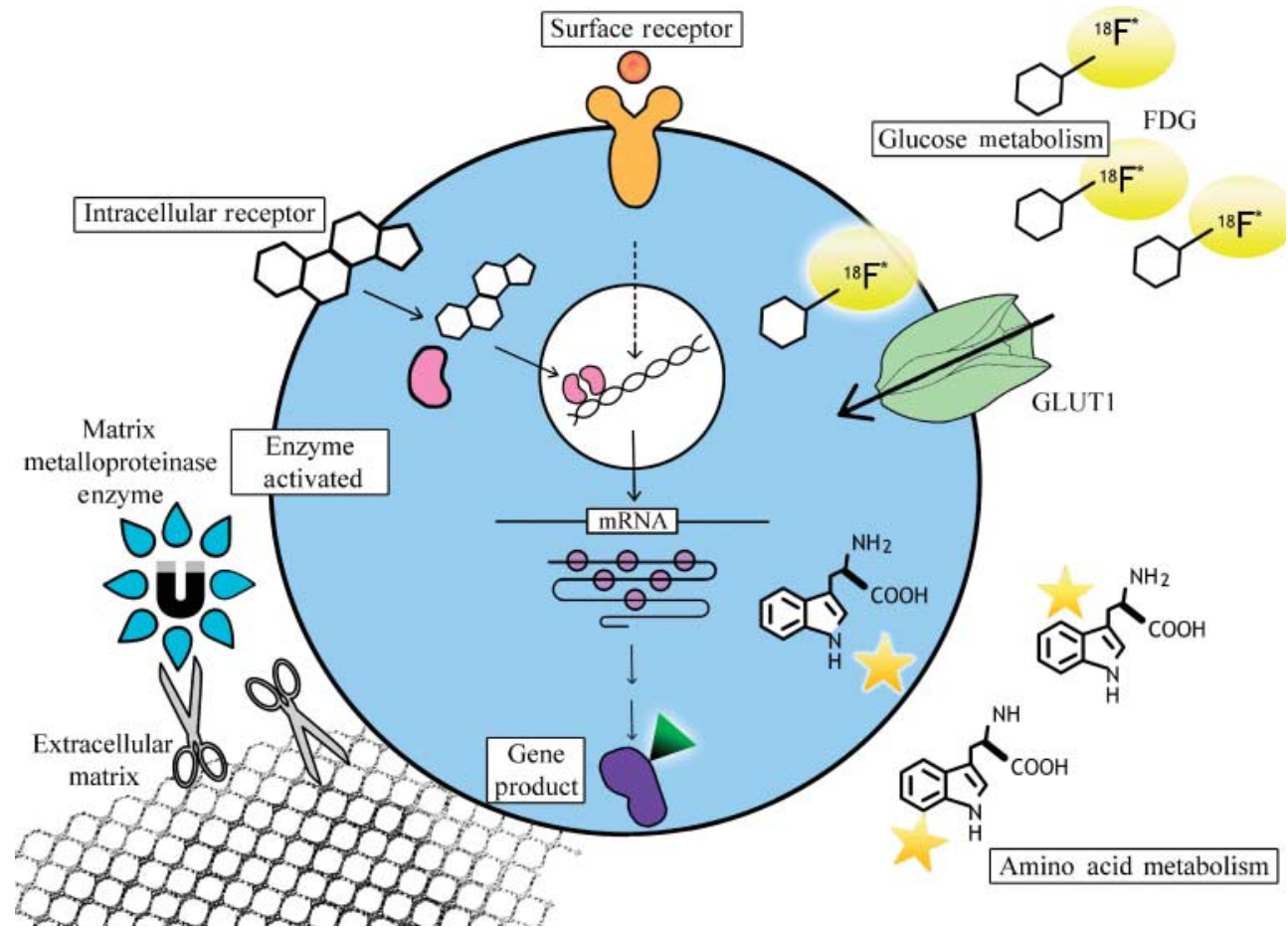

Figure 1 Major classifications of in vivo imaging agents for evaluating function. The basic concept behind several methods of functional imaging is shown. The PET agent FDG is transported through GLUT channels and trapped inside the cell to demonstrate glucose metabolism. In neuroendocrine tumors, accumulation of metabolites of several amino acids allows for functional imaging. For diseases with receptor overexpression, imaging agents that bind to either extracellular or intracellular targets offer insight into the expression level of the receptor and possible downstream pathways. Enzyme-activated reporters indicate the function of the protein, for example, matrix metalloproteinases activate reporter agent while degrading extracellular proteins. Finally, reporter genes containing a regulatory element in the promoter linked to an easily assayed protein, such as green fluorescent protein, luciferase, or $\beta$-galactosidase. When the gene of interest is transcribed, the reporter protein is activated and can be easily quantified in vivo. 
Table 1 Advantages and disadvantages of imaging modalities used for functional imaging

Advantages

Imaging modality

Bioluminescence

Fluorescence

MRI

PET

SPECT

\author{
Spatial and temporal information \\ Low non-specific luminescence \\ Monitors cell viability \\ Low cost \\ No tissue damage \\ Multiple fluorophores \\ High spatial resolution \\ Well tolerated \\ Excellent delineation of anatomical \\ structures \\ High sensitivity \\ Readily reaches target \\ High sensitivity
}

Disadvantages

Enzyme most commonly used not naturally in humans: engineered Requires injectable substrates and cofactors

Diffraction and penetration through organs difficult Non-specific fluorescence

Low (milli or micro molar) sensitivity

Mostly restricted to extracellular domains

Requires radioactivity

Low spatial resolution

Requires radioactivity

Less quantifiable than PET bladder where excretion of the agent can obscure imaging (Israel \& Kuten 2007). Finally, FDG more specifically marks cells that express the GLUT-1 transporter as opposed to having a higher metabolism and therefore macrophages and sites of inflammation are sometimes confused for tumors. Often neoplastic cells have altered biochemical pathways that result in the upregulation of the GLUT, altered glucose metabolism and even alterations in glycolytic enzymes associated with the hypoxic environment that may activate metabolic steps (Pauwels et al. 1998). Despite these drawbacks, FDG remains the most highly utilized functional imaging agent and demonstrates that a known endocrine process can be exploited to develop in vivo imaging tools.

\section{Amino acid metabolism}

One of the hallmarks of neuroendocrine tumors is the uptake and metabolism of amino acids into their decarboxylated forms also known as amine precursor uptake and decarboxylation (APUD). The term APUD defines a series of cells with endocrine functions based on the secretion of amine or polypeptide hormones. The neuroendocrine tumors include carcinoid tumors, paragangliomas, medullary thyroid carcinomas, and pancreatic islet cell tumors (Tamm et al. 2007). Neuroendocrine tumors show a high uptake and metabolism of two wellcharacterized agents, ${ }^{11} \mathrm{C}-\mathrm{L}-\mathrm{dopa}$ and ${ }^{18} \mathrm{~F}$-L-DOPA (Becherer et al. 2004). PET imaging can successfully image the neuroendocrine tumor tissue and some of the metastases including those in the liver, lymph, and bone clinically (Nanni et al. 2006). Another amino acid utilized in the study of neuroendocrine tumors is the ${ }^{11}$ C-5-hydroxytryptophan (5-HTP) serotonin derivative (Sundin et al. 2007). In comparative studies, PET imaging with ${ }^{11} \mathrm{C}-5$-HTP had a higher sensitivity than computed tomography (CT) and better determined liver metastases
(Orlefors et al. 1998). The ability of ${ }^{11} \mathrm{C}-5$-HTP to image both primary tumors and metastasis was superior to that of the L-dopa compound; however, excretion of the tracers in the urine obscured detection of kidney satellite populations of tumor cells (Sundin et al. 2004, Krausz \& Israel 2006). Studies utilizing a compound called carbidopa, an inhibitor of the urinary metabolite of ${ }^{11}$ C-5-HTP, significantly reduced renal signal obstruction and increased the concentration of the PET agent in the tumor (Orlefors et al. 2006). Amino acid and glucose metabolism are both examples of how a known function or genetic alteration in endocrine disorders can be exploited by in vivo imaging agents such that they accumulate and are targeted to specific cell types for functional imaging.

\section{Cell surface receptors}

Cell surface receptors represent one type of target for imaging agents that provide information about signal pathway expression (Groves et al. 2007). While the expression of the receptor alone is often an important parameter for staging and disease diagnosis, it does not directly indicate pathway activation. However, internalization of receptors in response to ligand binding is one mechanism for sequestering imaging agents. In addition, overexpression of a receptor often represents the upregulation of the gene encoding for that receptor, which frequently corresponds with the aggressive state of a tumor.

Somatostatin receptors have been identified on the surface of many neuroendocrine tumors and represent a valid target for imaging. The most common analog produced to bind to somatostatin receptors is octreotate ( ${ }^{111}$ In-pentetreotide), which preferentially binds type 2 somatostatin receptors (Rufini et al. 2006). New variations on the ${ }^{111}$ In-labeled drug utilizing 
beta-emitting radiolabels like ${ }^{90} \mathrm{Y}$ or ${ }^{177} \mathrm{Lu}$ improve the therapeutic profile such that decreases in tumor size after treatment can be measured using ${ }^{111}$ In-labeled existing PET tracers in the clinic (Van Essen et al. 2007). Whole-body imaging can be performed after administration of the agent to visualize tumors and metastasis expressing high levels of the receptor (de Herder et al. 2005). Identifying small metastatic populations of cells based on overexpression of a cell surface receptor is a major breakthrough for in vivo imaging agents.

Tyrosine kinase receptors are another popular cell surface target for the treatment of both breast and prostate cancers. Many generations of preclinical epidermal growth factor (EGF) imaging agents targeting the receptor family have been engineered as well as combinations of imaging agents including PET, SPECT, MRI, and CT (Cai et al. 2007). Both endogenous ligands and drugs have been coupled to various imaging modalities to measure EGF receptors. The monoclonal antibody herceptin (trastuzumab) has also been used to create an imaging agent specific for the Her-2/neu (ErbB2) receptor (Artemov et al. 2003a,b, Funovics et al. 2004). Due to the incredibly complicated signaling network regulated by the EGF receptor family and the cross-talk with other signaling pathways, expression of these receptors may not translate into valuable information for treatment. Therefore, the tyrosine kinase family of imaging agents offers one key example of how imaging a receptor may provide little information on specific downstream pathways, because the receptor is present in many isoforms that each activate unique and complicated signaling cascades. However, expression of the receptor and its subsequent inactivation does have therapeutic potential in mitigating cancers regardless of the downstream pathway information thus illustrating the goal of imaging receptors in the absence of specific downstream signaling information.

\section{Intracellular receptors}

Intracellular receptors are a separate category of imaging agents that must both target a relevant binding partner and cross the cell membrane. The estrogen receptor is an intracellular receptor that is used to diagnose and stage breast cancers. Because the current methodologies for screening estrogen and progesterone receptor require invasive biopsies, identification of an in vivo imaging agent could improve the diagnosis of the disease. Several PET imaging agents have been developed preclinically to evaluate the expression of these nuclear intracellular receptors such as ${ }^{18} \mathrm{~F}$-fluoroestradiol, ${ }^{99} \mathrm{mTc}$, and ${ }^{68} \mathrm{Ga}$-flutamate peptide-estradiol, and ${ }^{18} \mathrm{~F}-16$ a-ethyl-19-norprogesterone (Jonson \& Welch 1998, Hostetler et al. 1999, Jonson et al. 1999, Skaddan et al. 2000). While many of these molecules have been plagued with metabolic inactivation, binding to serum hormone binding globulin, and poor chemical synthetic yield, positive results have been reported for 18-fluoroestradiol (FES). A study performed on two patients utilizing ${ }^{18}$ F-FES and ${ }^{18}$ F-FDG detected metabolically inactive, estrogen receptor (ER)-positive tumor populations (Kumar et al. 2007). Two MRI agents have been developed for targeting progesterone receptor, but both need validation that they can detect subtle changes in receptor levels before their ability to image tumors can be substantiated (Lee et al. 2005, 2007). MRI generally is considered not sensitive enough to detect small changes in receptor concentration but immobilization and concentration inside of cells in the low micromolar dose might still generate viable images (Hanaoka et al. 2008). Radiolabeled tamoxifen agents have also been derived for PET imaging and may improve treatment decisions for patients responsive to the therapy (Van de Wiele et al. 2001). Aromatase imaging agents are under investigation preclinically and current options take advantage of binding inhibition to demonstrate where the aromatase protein is expressed as opposed to monitoring the enzyme activity (Takahashi et al. 2006, Wang et al. 2007). Androgen receptor PET agents have also been created but indicate whether a therapy is reducing androgen levels as opposed to staging prostate cancers, because androgen receptors are usually present even in androgen-independent cancers (Van Den Bossche \& Van de Wiele 2004, Parent et al. 2007). Prostate cancer differs from some other hormonally regulated cancers in that it retains expression of the androgen receptor even in the context of low circulating androgens (Kaarbo et al. 2007). Importantly, while steroid receptors are often important in the staging and responsiveness of endocrine-related cancers, they may also be utilized to study developmental processes and other diseases due to their broad activity in endocrinology (Takahashi et al. 2007).

\section{Enzyme catalysis}

One specific methodology for imaging function involves capturing the activity of enzymes important in endocrinology (Torigian et al. 2007). Most of the enzymeactivated agents are designed to demonstrate the activity of proteins important in cancer biology. However, the general concept of applying functional groups onto imaging agents for activation by an enzyme has broadranging implications for the field of endocrinology. For example, the matrix metalloproteinases are critical molecules in development and cancer, which allow cells to degrade extracellular matrix proteins and invade surrounding areas. Enzyme-activated matrix metalloproteinase (MMP) tracers are now in the development 
of both the MR and PET fields as diagnostic tools for human disease (Breyholz et al. 2007). Another enzyme activity imaging strategy involves caspases, enzymes responsible for DNA degradation during apoptosis (Faust et al. 2007). The imaging probe selectively binds to the activated enzyme thereby demonstrating where in vivo apoptosis is occurring as part of disease or therapy. A final example uses an enzyme-activated form of the substrate for $\beta$-galactosidase. When a sugar moiety is cleaved by the $\beta$-galactosidase enzyme, a gadolinium ion in the imaging agent is now capable of interacting with water molecules increasing $\mathrm{T} 1$ signal enhancement using MR (Louie et al. 2000). Generating enzyme-activated substrates offers one of the most promising methods for measuring function as it focuses on the protein activity rather than the amount of a receptor or a transporter (Louie 2006). However, the field is still developing and reagents directly applicable for endocrine diseases are still sparse.

\section{Gene promoters via marker proteins}

The imaging field is most likely to generate functional data in the area of reporter gene constructs. The system usually combines a reporter protein, which is an easily assayed gene, controlled by a regulatory element of a promoter of interest (Fig. 2; Rome et al. 2007). Expression of the gene is measured and correlates with the transcriptional activity of the gene under investigation. The most common reporter proteins are green fluorescent protein (GFP), luciferase, thymidine kinase, and $\beta$-galactosidase. The choice of the reporter and the specific agent or biological process used to activate the expression will influence whether the system is imaged with PET, MRI, or optical techniques. Because expression relies on the genetic engineering of the reporter and the promoter, most applications are relevant to animal models and cell lines. First, the technology can be applied at both the cellular and whole-body level. Neurons

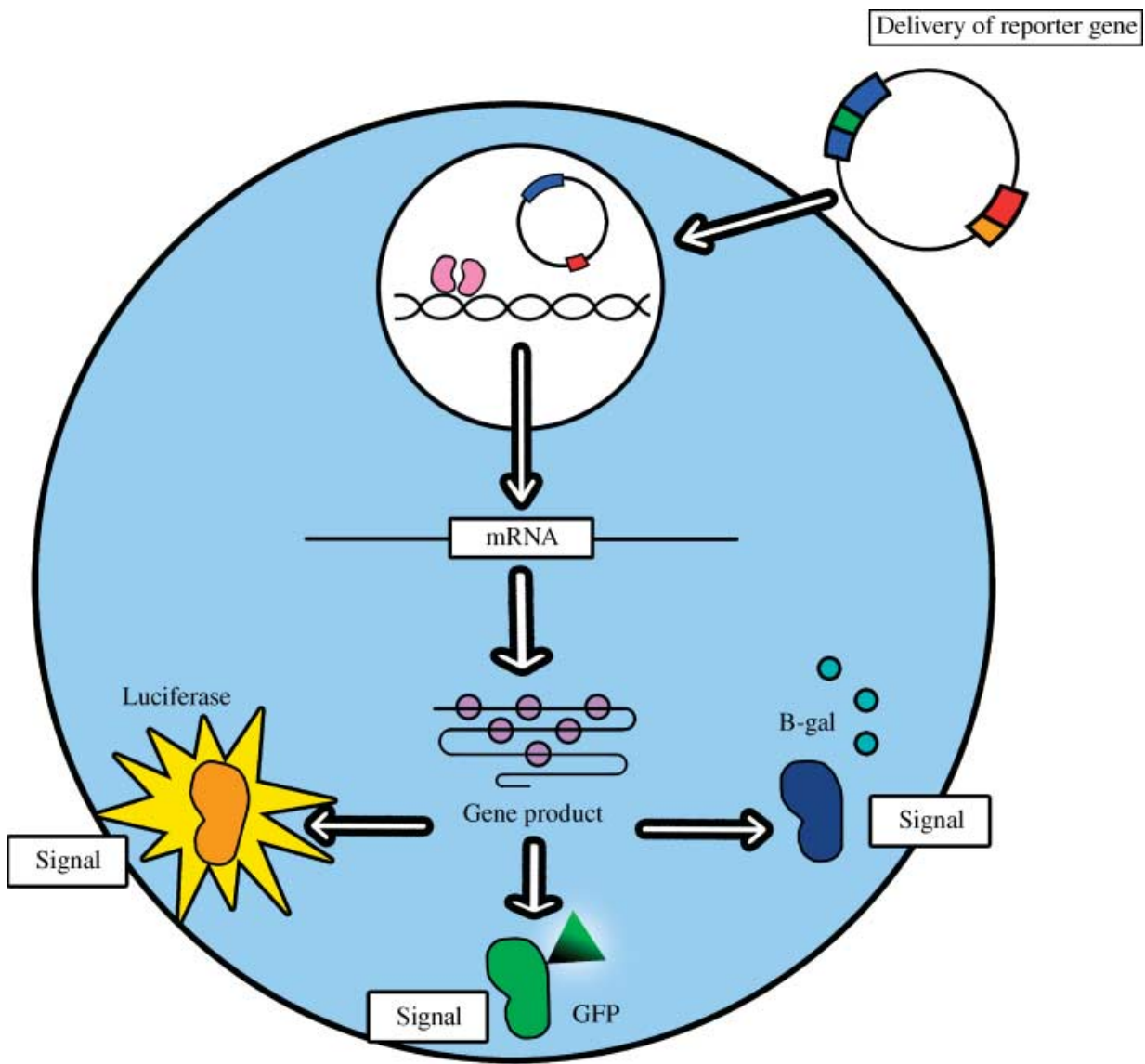

Figure 2 Basic strategy for utilizing reporter gene as in vivo imaging agent. The reporter gene contains the promoter of a gene of interest linked to an easily assayed protein. The reporter gene is then transfected into the target cell through transgene expression in a mouse, introduction by a virus, or transiently into cell populations. Promoters can be constantly activated or inducible so that function could be imaged continuously or during a specific biological process. Reporters are then detected usually in the presence of the substrate for the reporter protein, i.e., luciferin is injected into mice expressing luciferase. The functional activation of the reporter is then imaged accordingly based on the selected protein. 
responsible for responding to glucocorticoid in the hippocampal portion of the brain have been imaged using GFP driven by a specific promoter to detect neuroendocrine function in vivo (Nishi et al. 2007). The in vivo differentiation of sexually dimorphic gonads was similarly visualized using the GATA-4 promoter linked to GFP in mice (Mazaud Guittot et al. 2007). When the promoter is expressed in many tissues then whole-body imaging can be developed. The vascular endothelial growth factor (VEGF) promoter was linked to GFP and illustrated the importance of this gene during vascularization of the human embryo and again during mammary carcinogenesis (Faley et al. 2007). The luciferase and $\beta$-galactosidase genes have been introduced into mice under the control of the estrogen response element creating animals with bioluminescence or colorimetric changes in tissues that are activated by estrogens, genistein, and bisphenol A (Ciana et al. 2001, 2003, Nagel et al. 2001, Lemmen et al. 2004b). The ERE-reporter mice have been instrumental in elucidating where and when estrogens act in both males and females during development and after exposure to environmental toxins (Ciana et al. 2003, Lemmen et al. 2004a). Whole-body imaging can be time dependent when the reporter construct is not visualized unless its substrate has been injected and then the promoter of interest is depicted in a tissue- and time-specific manner (Zhang et al. 2001). Chemical modifications of luciferase are now available such that the protein is secreted allowing for its quantification in the serum of transgenic animals (Wurdinger et al. 2008). The generation of reporter technology for animals and cell lines is almost boundless, however, the requirement to have transgenic promoters driving expression of a reporter protein limits its direct application in humans. A major advantage of utilizing reporter genes is that the signal demonstrates that the protein required for luminescence is functional in vivo and that the promoter driving its expression is activated in the physiological context.

\section{Cell tracking}

Stem cells, cultured primary cells, or any therapeutic cells engineered with reporter genes can be utilized to image populations reintroduced into the human, so they may non-invasively be trafficked and identified. When individuals have cells transplanted into diseased tissue for regrowth, such as $\beta$-islet transplantation, the cells can be labeled with different reporter proteins to indicate whether the transplant is in the correct location (Acton \& Zhou 2005). Pancreatic cells labeled with GFP and luciferase have been utilized both to study development and tissue survival (Puri \& Hebrok 2007). In the field of reproductive biology, fertility studies indicating the viability of cryopreserved and vitrified green fluorescent eggs have been reported after transplantation into wildtype animals (Hani et al. 2006). Utilizing reporter genes to display whether a transplanted tissue or cell type remains viable or trafficked to the correct location offers a promising clinical application for in vivo imaging of function in endocrinology.

\section{Multimodal approaches}

With the advent of new technologies, the opportunity to combine approaches and generate sophisticated targeted imaging agents is possible. Probably the most exciting use of in vivo imaging will combine multiple types of technologies and imaging approaches to generate information with the highest possible specificity, resolution, and targeted biological function. Each imaging modality has positive and negative attributes in terms of spatial resolution, image intensity, sensitivity, and the clearance rate from the body (Frullano \& Meade 2007). In addition, the technique used might favor one imaging modality over another (Seevinck et al. 2007). Multimodal agents might conjugate two imaging tracers together such that one molecule contains both a PET and MR ion. Alternatively, the imaging agents could combine nuclear tracers (PET) and optical imaging molecules like tetramethylrhodamine. Surgical removal of a tumor with a specific signature of receptors and transporters could be identified through PET or MR and then during the procedure further demarcated under fluorescent light with optical imaging to fine tune the resection (Josephson et al. 2002, Kircher et al. 2003). Combining more than one type of scan with CTand PET, or MRI might integrate superior imaging modalities for localization and functional properties of the diseased tissue (Acton \& Zhou 2005). For example, X-ray tomography and MR imaging might provide the best contrast of both the bone and soft tissue. If multiple functional imaging modalities were utilized, a combination of attributes about a diseased organ could be explored. For example, a breast tumor could be imaged for estrogen and progesterone receptors with two agents, or a tumor could be quantified for metabolic activity and expression of the Her2/neu receptor. Multimodal agents might also integrate aspects of therapy along with imaging properties, so that the efficacy of a drug to shrink a tumor might be imaged in vivo (Frullano et al. 2006). Multimodal applications could also link one imaging strategy with an alternative method of measurement such as the creation of a secreted form of luciferase that can be measured quantitatively in the blood upon transgene activation (Wurdinger et al. 2008). The application could be extended even further in the presence of transgenic cell lines and animal models to study the development of one organ, the action of a drug on that organ, and the 
effect of the drug on the physiology of the tissue in vivo (Dickinson 2006).

\section{Conclusions}

Endocrinology is a fast-growing field. The technologies are now being developed to determine the gene expression and function of important biomarkers for endocrine disorders. As more technologies develop in the preclinical stage, the opportunity will arise for imaging to increase individualized medicine with clinicians utilizing specific functional imaging agents to identify the location and exact alteration in a person's health. In some cases, the imaging breakthroughs will improve upon quantitation, while others will elucidate a function gone awry as in cancer or glucose metabolism. Because more types of imaging will be utilized together in a cogent manner to describe human health, the integration of technology and researchers at all levels will be critical. The field will rely heavily in the future on the integration of many areas of science including biology, chemistry, imaging, pharmacokinetic clearance, and medicine. Another challenge will be developing technologies that have succeeded in small animal models to the phase where they are applicable to humans. The process of bringing each new imaging agent through Food and Drug Administration approval for use in the clinic could be hastened by combining existing agents using multimodal approaches. Endocrinology will benefit greatly from enhanced early detection, functional analysis, and localization of signaling changes that the field of imaging brings to this diverse discipline.

\section{Acknowledgements}

NIH Support: This work was supported in part by Grant \#08-08 from the American Cancer Society, Illinois Division, Inc. as well as the NIH K12HD055892 Building Interdisciplinary Research Careers in Women's Health from the Office of Women's Health Research and National Institute of Child Health and Human Development. The authors declare that there is no conflict of interest that would prejudice the impartiality of this scientific work.

\section{References}

Acton PD \& Zhou R 2005 Imaging reporter genes for cell tracking with PET and SPECT. Quarterly Journal of Nuclear Medicine and Molecular Imaging 49 349-360.

Allen MJ \& Meade TJ 2003 Synthesis and visualization of a membranepermeable MRI contrast agent. Journal of Biological Inorganic Chemistry 8 746-750.

Allen MJ \& Meade TJ 2004. Metal Ions in Biological Systems, New York: Fontis Media.
Allen MJ, MacRenaris KW, Venkatasubramanian PN \& Meade TJ 2004 Cellular delivery of MRI contrast agents. Chemistry $\mathcal{E}$ Biology 11 301-307.

Artemov D, Mori N, Okollie B \& Bhujwalla ZM $2003 a$ MR molecular imaging of the Her-2/neu receptor in breast cancer cells using targeted iron oxide nanoparticles. Magnetic Resonance in Medicine 49 403-408.

Artemov D, Mori N, Ravi R \& Bhujwalla ZM 2003b Magnetic resonance molecular imaging of the HER-2/neu receptor. Cancer Research 63 2723-2727.

Becherer A, Szabo M, Karanikas G, Wunderbaldinger P, Angelberger P, Raderer M, Kurtaran A, Dudczak R \& Kletter K 2004 Imaging of advanced neuroendocrine tumors with (18)F-FDOPA PET. Journal of Nuclear Medicine 45 1161-1167.

Blasberg R 2002 PET imaging of gene expression. European Journal of Cancer 38 2137-2146.

Van Den Bossche B \& Van de Wiele C 2004 Receptor imaging in oncology by means of nuclear medicine: current status. Journal of Clinical Oncology 22 3593-3607.

Breyholz HJ, Wagner S, Levkau B, Schober O, Schafers M \& Kopka K $2007 \mathrm{~A}{ }^{18}$ F-radiolabeled analogue of CGS $27023 \mathrm{~A}$ as a potential agent for assessment of matrix-metalloproteinase activity in vivo. Quarterly Journal of Nuclear Medicine and Molecular Imaging 51 24-32.

Cai W, Niu G \& Chen X 2007 Multimodality imaging of the HER-kinase axis in cancer. European Journal of Nuclear Medicine and Molecular Imaging 35 186-208.

Ciana P, Di Luccio G, Belcredito S, Pollio G, Vegeto E, Tatangelo L, Tiveron C \& Maggi A 2001 Engineering of a mouse for the in vivo profiling of estrogen receptor activity. Molecular Endocrinology 15 1104-1113

Ciana P, Raviscioni M, Mussi P, Vegeto E, Que I, Parker MG, Lowik C \& Maggi A 2003 In vivo imaging of transcriptionally active estrogen receptors. Nature Medicine 9 82-86.

Dickinson ME 2006 Multimodal imaging of mouse development: tools for the postgenomic era. Developmental Dynamics 235 2386-2400.

Doubrovin M, Ponomarev V \& Blasberg RG 2004 PET-based reporter gene imaging. Assessment of endogenous molecular-genetic events. IEEE Engineering in Medicine and Biology Magazine 23 38-50.

Eriksson B, Orlefors H, Oberg K, Sundin A, Bergstrom M \& Langstrom B 2005 Developments in PET for the detection of endocrine tumours. Best Practice and Research. Clinical Endocrinology and Metabolism 19 311-324.

Van Essen M, Krenning EP, De Jong M, Valkema R \& Kwekkeboom DJ 2007 Peptide receptor radionuclide therapy with radiolabelled somatostatin analogues in patients with somatostatin receptor positive tumours. Acta Oncologica 46 723-734.

Faley SL, Takahashi K, Crooke CE, Beckham JT, Tomemori T, Shappell SB, Jansen ED \& Takahashi T 2007 Bioluminescence imaging of vascular endothelial growth factor promoter activity in murine mammary tumorigenesis. Molecular Imaging 6 331-339.

Faust A, Wagner S, Law MP, Hermann S, Schnockel U, Keul P, Schober O, Schafers M, Levkau B \& Kopka K 2007 The nonpeptidyl caspase binding radioligand (S)-1-(4-(2-[ $\left[{ }^{18} \mathrm{~F}\right]$ Fluoroethoxy)-benzyl)-5-[1(2-methoxymethylpyrrolidinyl)s ulfonyl $]$ isatin $\left(\left[{ }^{18} \mathrm{~F}\right] \mathrm{CbR}\right)$ as potential positron emission tomography-compatible apoptosis imaging agent. Quarterly Journal of Nuclear Medicine and Molecular Imaging 51 67-73.

Frullano L \& Meade TJ 2007 Multimodal MRI contrast agents. Journal of Biological Inorganic Chemistry 12 939-949.

Frullano L, Tejerina B \& Meade TJ 2006 Synthesis and characterization of a doxorubicin-Gd(III) contrast agent conjugate: a new approach toward prodrug-procontrast complexes. Inorganic Chemistry $\mathbf{4 5}$ 8489-8491

Funovics MA, Kapeller B, Hoeller C, Su HS, Kunstfeld R, Puig S \& Macfelda K 2004 MR imaging of the her2/neu and 9.2.27 tumor antigens using immunospecific contrast agents. Magnetic Resonance Imaging 22 843-850. 
Groves AM, Win T, Haim SB \& Ell PJ 2007 Non- $\left[{ }^{18}\right.$ F]FDG PET in clinical oncology. Lancet Oncology 8 822-830.

Hanaoka K, Lubag AJ, Castillo-Muzquiz A, Kodadek T \& Sherry AD 2008 The detection limit of a $\mathrm{Gd}(3+)$-based $\mathrm{T}(1)$ agent is substantially reduced when targeted to a protein microdomain. Magnetic Resonance Imaging (Epub Jan 31).

Hani T, Tachibe T, Shingai S, Kamada N, Ueda O \& Jishage K 2006 Fertility of mice receiving vitrified adult mouse ovaries. Reproduction 131 681-687.

de Herder WW, Kwekkeboom DJ, Valkema R, Feelders RA, van Aken MO, Lamberts SW, van der Lely AJ \& Krenning EP 2005 Neuroendocrine tumors and somatostatin: imaging techniques. Journal of Endocrinological Investigation 28 132-136.

Herschman HR 2004 PET reporter genes for noninvasive imaging of gene therapy, cell tracking and transgenic analysis. Critical Reviews in Oncology/Hematology 51 191-204.

Hostetler ED, Jonson SD, Welch MJ \& Katzenellenbogen JA 1999 Synthesis of 2-[(18)F]fluoroestradiol, a potential diagnostic imaging agent for breast cancer: strategies to achieve nucleophilic substitution of an electron-rich aromatic ring with $[(18) \mathrm{F}] \mathrm{F}(-)$. Journal of Organic Chemistry 64 178-185.

Israel O \& Kuten A 2007 Early detection of cancer recurrence: ${ }^{18}$ F-FDG $\mathrm{PET} / \mathrm{CT}$ can make a difference in diagnosis and patient care. Journal of Nuclear Medicine 48 28S-35S.

Jonson SD \& Welch MJ 1998 PET imaging of breast cancer with fluorine-18 radiolabeled estrogens and progestins. Quarterly Journal of Nuclear Medicine 42 8-17.

Jonson SD, Bonasera TA, Dehdashti F, Cristel ME, Katzenellenbogen JA \& Welch MJ 1999 Comparative breast tumor imaging and comparative in vitro metabolism of 16 alpha- $\left[{ }^{18} \mathrm{~F}\right]$ fluoroestradiol17 beta and 16beta- $\left[{ }^{18} \mathrm{~F}\right]$ fluoromoxestrol in isolated hepatocytes. Nuclear Medicine and Biology 26 123-130.

Josephson L, Kircher MF, Mahmood U, Tang Y \& Weissleder R 2002 Near-infrared fluorescent nanoparticles as combined MR/optical imaging probes. Bioconjugate Chemistry 13 554-560.

Kaarbo M, Klokk TI \& Saatcioglu F 2007 Androgen signaling and its interactions with other signaling pathways in prostate cancer. Bioessays 29 1227-1238.

Kircher MF, Mahmood U, King RS, Weissleder R \& Josephson L 2003 A multimodal nanoparticle for preoperative magnetic resonance imaging and intraoperative optical brain tumor delineation. Cancer Research 63 8122-8125.

Krausz Y \& Israel O 2006 Single-photon emission computed tomography/computed tomography in endocrinology. Seminars in Nuclear Medicine 36 267-274.

Kumar P, Mercer J, Doerkson C, Tonkin K \& McEwan AJ 2007 Clinical production, stability studies and PET imaging with 16-alpha$\left[{ }^{18} \mathrm{~F}\right]$ fluoroestradiol $\left(\left[{ }^{18} \mathrm{~F}\right] \mathrm{FES}\right)$ in ER positive breast cancer patients. Journal of Pharmacy $\mathcal{E}$ Pharmaceutical Sciences 10 256s-265s.

Lee J, Zylka MJ, Anderson DJ, Burdette JE, Woodruff TK \& Meade TJ 2005 A steroid-conjugated contrast agent for magnetic resonance imaging of cell signaling. Journal of the American Chemical Society 127 13164-13166.

Lee J, Burdette JE, MacRenaris KW, Mustafi D, Woodruff TK \& Meade TJ 2007 Rational design, synthesis, and biological evaluation of progesterone-modified MRI contrast agents. Chemistry E Biology 14 824-834.

Lemmen JG, Arends RJ, van der Saag PT \& van der Burg B $2004 a$ In vivo imaging of activated estrogen receptors in utero by estrogens and bisphenol A. Environmental Health Perspectives 112 1544-1549.

Lemmen JG, Arends RJ, van Boxtel AL, van der Saag PT \& van der Burg B $2004 b$ Tissue- and time-dependent estrogen receptor activation in estrogen reporter mice. Journal of Molecular Endocrinology 32 689-701.

Lewington VJ \& Clarke SE 2001 Isotopic evaluation and therapy in patients with malignant endocrine disease. Best Practice and Research. Clinical Endocrinology and Metabolism 15 225-239.
Louie A 2006 Design and characterization of magnetic resonance imaging gene reporters. Methods in Molecular Medicine 124 401-417.

Louie AY, Huber MM, Ahrens ET, Rothbacher U, Moats R, Jacobs RE, Fraser SE \& Meade TJ 2000 In vivo visualization of gene expression using magnetic resonance imaging. Nature Biotechnology 18 321-325.

Mankoff DA, Eary JF, Link JM, Muzi M, Rajendran JG, Spence AM \& Krohn KA 2007 Tumor-specific positron emission tomography imaging in patients: $\left[{ }^{18} \mathrm{~F}\right]$ fluorodeoxyglucose and beyond. Clinical Cancer Research 13 3460-3469.

Mazaud Guittot S, Tetu A, Legault E, Pilon N, Silversides DW \& Viger RS 2007 The proximal Gata4 promoter directs reporter gene expression to sertoli cells during mouse gonadal development. Biology of Reproduction 76 85-95.

Nagel SC, Hagelbarger JL \& McDonnell DP 2001 Development of an ER action indicator mouse for the study of estrogens, selective ER modulators (SERMs), and Xenobiotics. Endocrinology 142 4721-4728.

Nanni C, Rubello D, Fanti S, Farsad M, Ambrosini V, Rampin L, Banti E, Carpi A, Muzzio P \& Franchi R 2006 Role of ${ }^{18}$ F-FDG-PET and PET/CT imaging in thyroid cancer. Biomedicine $\mathcal{E}$ Pharmacotherapy 60 409-413.

Nishi M, Usuku T, Itose M, Fujikawa K, Hosokawa K, Matsuda KI \& Kawata M 2007 Direct visualization of glucocorticoid receptor positive cells in the hippocampal regions using green fluorescent protein transgenic mice. Neuroscience 146 1555-1560.

Orlefors H, Sundin A, Ahlstrom H, Bjurling P, Bergstrom M, Lilja A, Langstrom B, Oberg K \& Eriksson B 1998 Positron emission tomography with 5-hydroxytryprophan in neuroendocrine tumors. Journal of Clinical Oncology 16 2534-2541.

Orlefors H, Sundin A, Lu L, Oberg K, Langstrom B, Eriksson B \& Bergstrom M 2006 Carbidopa pretreatment improves image interpretation and visualisation of carcinoid tumours with ${ }^{11} \mathrm{C}-5$-hydroxytryptophan positron emission tomography. European Journal of Nuclear Medicine and Molecular Imaging 33 60-65.

Parent EE, Carlson KE \& Katzenellenbogen JA 2007 Synthesis of 7alpha-(fluoromethyl) dihydrotestosterone and 7alpha-(fluoromethyl)nortestosterone, structurally paired androgens designed to probe the role of sex hormone binding globulin in imaging androgen receptors in prostate tumors by positron emission tomography. Journal of Organic Chemistry 72 5546-5554.

Pauwels EK, Ribeiro MJ, Stoot JH, McCready VR, Bourguignon M \& Maziere B 1998 FDG accumulation and tumor biology. Nuclear Medicine and Biology 25 317-322.

Puri S \& Hebrok M 2007 Dynamics of embryonic pancreas development using real-time imaging. Developmental Biology 306 82-93.

Rome C, Couillaud F \& Moonen CT 2007 Gene expression and gene therapy imaging. European Radiology 17 305-319.

Rufini V, Calcagni ML \& Baum RP 2006 Imaging of neuroendocrine tumors. Seminars in Nuclear Medicine 36 228-247.

Seevinck PR, Seppenwoolde JH, de Wit TC, Nijsen JF, Beekman FJ, van Het Schip AD \& Bakker CJ 2007 Factors affecting the sensitivity and detection limits of MRI, CT, and SPECT for multimodal diagnostic and therapeutic agents. Anti-Cancer Agents in Medicinal Chemistry 7 317-334.

Skaddan MB, Wust FR, Jonson S, Syhre R, Welch MJ, Spies H \& Katzenellenbogen JA 2000 Radiochemical synthesis and tissue distribution of Tc-99m-labeled 7alpha-substituted estradiol complexes. Nuclear Medicine and Biology 27 269-278.

Sundin A, Eriksson B, Bergstrom M, Langstrom B, Oberg K \& Orlefors H 2004 PET in the diagnosis of neuroendocrine tumors. Annals of the New York Academy of Sciences 1014 246-257.

Sundin A, Garske U \& Orlefors H 2007 Nuclear imaging of neuroendocrine tumours. Best Practice and Research. Clinical Endocrinology and Metabolism 21 69-85. 
Takahashi K, Bergstrom M, Frandberg P, Vesstrom EL, Watanabe Y \& Langstrom B 2006 Imaging of aromatase distribution in rat and rhesus monkey brains with $\left[{ }^{11} \mathrm{C}\right]$ vorozole. Nuclear Medicine and Biology 33 599-605.

Takahashi N, Yang DJ, Kurihara H, Borne A, Kohanim S, Oh CS, Mawlawi O \& Kim EE 2007 Functional imaging of estrogen receptors with radiolabeled-GAP-EDL in rabbit endometriosis model. Academic Radiology 14 1050-1057.

Tamm EP, Kim EE \& Ng CS 2007 Imaging of neuroendocrine tumors. Hematology/Oncology Clinics of North America 21 409-432 vii.

Tohma T, Okazumi S, Makino H, Cho A, Mochiduki R, Shuto K, Kudo H, Matsubara K, Gunji H \& Ochiai T 2005 Relationship between glucose transporter, hexokinase and FDG-PET in esophageal cancer. Hepatogastroenterology $\mathbf{5 2}$ 486-490.

Torigian DA, Huang SS, Houseni M \& Alavi A 2007 Functional imaging of cancer with emphasis on molecular techniques. CA: A Cancer Journal for Clinicians 57 206-224.

Wang M, Lacy G, Gao M, Miller KD, Sledge GW \& Zheng QH 2007 Synthesis of carbon-11 labeled sulfonanilide analogues as new potential PET agents for imaging of aromatase in breast cancer. Bioorganic and Medicinal Chemistry Letters 17 332-336.
Van de Wiele C, Cocquyt V, Van den Broecke R, De Vos F, Van Belle S, Dhaene K, Slegers G \& Dierckx RA 2001 Iodine-labeled tamoxifen uptake in primary human breast carcinoma. Journal of Nuclear Medicine 42 1818-1820.

Wurdinger T, Badr C, Pike L, de Kleine R, Weissleder R, Breakefield XO \& Tannous BA 2008 A secreted luciferase for ex vivo monitoring of in vivo processes. Nature Methods 5 171-173.

Zhang W, Feng JQ, Harris SE, Contag PR, Stevenson DK \& Contag CH 2001 Rapid in vivo functional analysis of transgenes in mice using whole body imaging of luciferase expression. Transgenic Research 10 423-434.

Zhao S, Kuge Y, Mochizuki T, Takahashi T, Nakada K, Sato M, Takei T \& Tamaki N 2005 Biologic correlates of intratumoral heterogeneity in ${ }^{18}$ F-FDG distribution with regional expression of glucose transporters and hexokinase-II in experimental tumor. Journal of Nuclear Medicine 46 675-682.

Received in final form 26 March 2008

Accepted 31 March 2008

Made available online as an Accepted Preprint

31 March 2008 